\title{
Is solar power renewable and carbon-neutral: Evidence from a pilot solar tower plant in China under a systems view
}

\author{
Xudong $\mathrm{Wu}^{\mathrm{a}, \mathrm{b}}$, Chaohui $\mathrm{Li}^{\mathrm{c}, \mathrm{b}}$, Ling Shao ${ }^{\mathrm{d}}$, Jing Meng ${ }^{\mathrm{e}}$, Lixiao Zhang ${ }^{\mathrm{f}, *}$, Guoqian Chen ${ }^{\mathrm{b}, \mathrm{g}, *}$ \\ ${ }^{a}$ School of Soil and Water Conservation, Beijing Forestry University, Beijing 100083, China \\ ${ }^{\mathrm{b}}$ Laboratory of Systems Ecology and Sustainability Science, College of Engineering, \\ Peking University, Beijing 100871, China \\ ${ }^{c}$ Yenching Academy, Peking University, Beijing 100871, China \\ d School of Economics and Management, China University of Geosciences, \\ Beijing 100083, China \\ ${ }^{\mathrm{e}}$ The Bartlett School of Construction and Project Management, University College London, London \\ WC1E 7HB, UK \\ ${ }^{\mathrm{f}}$ State Key Joint Laboratory of Environmental Simulation and Pollution Control, \\ School of Environment, Beijing Normal University, Beijing 100875, China \\ ${ }^{g}$ Center for Research Excellence in Renewable Energy and Power Systems, \\ King Abdulaziz University, Jeddah, 21589, Saudi Arabia
}

\begin{abstract}
Solar power has been widely treated as renewable and carbon-neutral for being free of fossil resource inputs and causing no carbon emissions. Recent studies, however, qualitatively challenged the traditional thinking derived under a local-realism-based perspective. In response to the recent concerns, this study as a continuation of a previous work offers a systems view into comprehending the 'renewable' and 'carbon-neutral' characters of solar power by the case of a Chinese pilot solar power plant. Under the systems view, a solar power plant is positioned as an organic system fed by 'nutrients' from the macro economy that relies on exogenous non-renewable energy resources as environmental support. A quantitative framework for evaluating the renewability and carbonneutrality of solar power systems is proposed. A package of indicators is also devised, together with a retrospect of the history of methodological development. The non-renewable energy cost is revealed to be in magnitude 1.6 times as much as the electricity produced and the carbon emissions induced are also shown to be remarkable, implying that solar power is not as renewable and carbonneutral as generally perceived. In contrast to coal-based power, however, solar power still appears as a promising alternative: the non-renewable energy cost and carbon emission for per unit of electricity delivered are revealed as $55 \%$ and $64 \%$ of that by the reference coal-fired power generation system in China, respectively. The outcome of this work provides a well-adapted assessment framework and adds insights into the intuitive understanding of renewable-based electricity.
\end{abstract}

Keywords: Solar power; systems view; local-realism-based perspective; renewability; carbonneutrality.

\footnotetext{
${ }^{*}$ Corresponding authors.

E-mail addresses: zhanglixiao@bnu.edu.cn (Lixiao Zhang), gqchen@pku.edu.cn (Guoqian Chen).
} 
Word count: 10319

\begin{tabular}{|c|c|}
\hline \multicolumn{2}{|l|}{ Abbreviations } \\
\hline \multicolumn{2}{|l|}{ Acronyms } \\
\hline NEIED & Non-renewable Energy Investment in Energy Delivered \\
\hline REPA & Resource and Environmental Profile Analysis \\
\hline EROI & Energy Return on Investment \\
\hline MPS & Material Product System \\
\hline SNA & System of National Accounts \\
\hline BOS & Balance of System \\
\hline \multicolumn{2}{|l|}{ Units } \\
\hline $\mathrm{m}^{2}$ & Square meter \\
\hline $\mathrm{r} / \mathrm{min}$ & Revolutions per minute \\
\hline $\mathrm{g} \mathrm{CO}_{2}$-eq & Gram carbon dioxide equivalent \\
\hline $\mathrm{h}$ & Hour \\
\hline $\mathrm{MPa}$ & Megapascal \\
\hline $\mathrm{CNY}$ & Chinese Yuan \\
\hline MJ & Mega Joule \\
\hline $\mathrm{kW}$ & Kilowatt \\
\hline $\mathrm{kWh}$ & Kilowatt-hour \\
\hline MW & Megawatt \\
\hline GW & Gigawatt \\
\hline GWh & Gigawatt-hour \\
\hline \multicolumn{2}{|l|}{ Nomenclature } \\
\hline$N E I E D_{\text {renewable }}$ & $\begin{array}{l}\text { Non-renewable energy investment in energy delivered by } \\
\text { renewable energy systems }\end{array}$ \\
\hline$N E I E D_{\text {coal }}$ & $\begin{array}{l}\text { Non-renewable energy investment in energy delivered by coal- } \\
\text { fired electricity systems }\end{array}$ \\
\hline$N E I E D_{\text {avoided }}$ & $\begin{array}{l}\text { Non-renewable energy cost avoided for per unit of energy } \\
\text { delivered by renewable energy systems }\end{array}$ \\
\hline$C E_{\text {renewable }}$ & Carbon emissions of renewable energy systems \\
\hline$C E_{\text {coal }}$ & Carbon emissions of coal-fired power generation systems \\
\hline Input $_{j}$ & Monetary expenditure of the $j_{t h}$ input \\
\hline$N E_{j}$ & Non-renewable energy cost of the $j_{t h}$ input \\
\hline$\varepsilon_{j}$ & Non-renewable energy intensity of the $j_{t h}$ input \\
\hline$C E_{j}$ & Carbon emissions induced by the $j_{t h}$ input \\
\hline$\delta_{j}$ & Carbon emission intensity of the $j_{t h}$ input \\
\hline$E_{\text {output }}$ & Energy output \\
\hline$C E_{\text {intensity }}$ & Carbon emission intensity of renewable energy systems \\
\hline
\end{tabular}




\section{Introduction}

1.1. Understanding the 'renewable' character of renewable energy under a systems view

Entrusted with high expectations to substitute conventional non-renewable forms of energy supply, renewable energy has long been widely regarded as 'renewable' and capable of addressing climate change. Instead of depending on the buried dead organisms to fuel the economy, solar power, wind power, hydropower as well as other kinds of renewable energy alternatives are sought to use the rapidly replenishing renewable energy sources (solar radiation, wind, hydro, biomass, etc.) for energy delivery and are therefore believed to be free from consumption of non-renewable energy resources, thus capable of mitigating carbon emissions coming from fossil fuel combustion. In recent years, however, the widely-believed reality of a $100 \%$ renewable electricity system has been challenged to a great extent. Based on a very comprehensive review of related studies published to date, Heard et al. [1] concluded from the 24 representative cases that there is no guarantee that $100 \%$ renewable-electricity systems are in fact achievable. Analogically, in a recent hot article entitled 'Abandoning the concept of renewable energy' by Harjanne and Korhonen [2], the non-renewability of renewable energy is pointed out: any renewable energy system relies on machinery and material inputs out of the support of non-renewable energy resources and its renewability is destined not to be fully $100 \%$. Then a question arises: Why are there divisions on whether renewable energy is free from non-renewable energy cost or not? Before digging into the issue, it is of critical importance to distinguish two terms, i.e., renewable energy source and renewable energy.

Renewable energy sources refer to primary energy sources that are continuously replenished by nature on a human time-scale to overcome the resource depletion caused by consumption, either through biological reproduction or other spontaneous processes [3, 4]. Solar radiation, wind, biomass, tides, waves, and geothermal heat are typical renewable energy sources. With regard to the term 'renewable energy', it means the usable forms of non-primary energy, such as solar-, windbased electricity, hydropower, and bioethanol that are physically generated from renewable energy sources [5]. As seen, a key difference lies between renewable energy sources and renewable energy. While renewable energy sources are ecological resources pertaining to the environment outside the human's socio-economic system, renewable energy could be regarded as the product of the economic utility of primary energy resources (including both non-renewable and renewable energy resources) and other ecological resources within the economic system. The whole process could be comprehended as below: The primary energy resources pass through the interface between the environment and the economy immediately after exploitation, and could be regarded as leaving the environment and 'used' by the economy; the economic utility of the primary energy resources becomes a dynamic part of the economy and circulates along with the commodity flows within the whole economic network via sectoral interlinkages, supporting the production process of the entire economic supply chain, just as noted by Herendeen [6]. In this way, the whole economy could be thus portrayed as a network of energy use flows with primary energy resources as exogenous environmental support. The non-primary energies, whether solar power, wind power, or bioethanol that are generally referred to as renewable energy, or fossil-fueled electricity and diesel that are referred to as second or tertiary energies, are identical to all other commodities, which are merely economic products supported by primary non-renewable energy resources.

As seen, though the rapidly replenishing renewable energy sources could be regarded as inexhaustible and clean compared to fossil energy resources, this may not apply to solar power, wind power and biofuel as renewable energy alternatives. These renewable alternatives as the products of the economy are supported by non-renewable energy resources as well as other kinds of resources. This is somewhat counter-intuitive as most people perceive renewable energy under a local-realism perspective: attention has been only focused on the onsite field at which nonrenewable energy consumption does not occur [7]. However, when the boundary of the renewable energy system is extended to the entire economy, the reality becomes quite different. For instance, 
steel, iron, silica, glass and other materials are required to manufacture some critical components (wind turbines, transformers, solar panels) of renewable-based electricity systems [8]. To manufacture iron or steel, non-renewable energy consumption is directly induced onsite to process iron ore and offsite for ore mining from the earth and transportation to the smelting furnace. Under a systems view, therefore, a renewable energy system would not be able to be free from nonrenewable energy costs and be carbon-neutral.

Proposed by Chen et al. [9], an indicator of non-renewable energy investment in energy delivered (NEIED) is devised for measuring renewable energy systems' renewability, which is defined as the non-renewable energy used directly and indirectly in the producing processes divided by the energy output of the system. The higher this indicator, the less renewable the renewable energy system. Under some circumstances, the non-renewable energy cost of a renewable energy product may even surpass the energy contained in the final product in magnitude. Yang and Chen [10] revealed that the non-renewable energy used to produce corn-ethanol is 1.7 times as much as the energy contained in corn-ethanol that is used as a replacement to gasoline. By taking into consideration the non-renewable energy used for water consumption and transportation, the total non-renewable energy consumption may escalate to 3.64 times of the energy delivered. In this regard, the high non-renewability instead of the widely-believed renewability is revealed for cornethanol. In a subsequent study [11], a net positive amount of carbon emission is revealed for cornethanol production under the systems view, which corresponds to an increase of around six times in emissions when corn-ethanol is resorted to as a substitute for gasoline and illustrates that cornethanol is far from carbon-neutral. With regard to other renewable alternatives, when examining them from a systems perspective, what is the reality in terms of renewability and carbon-neutrality as compared to the intuitive understanding?

\subsection{Non-renewable energy cost and carbon emissions induced by solar power}

Of all the renewable energies, solar power has become the fastest-growing energy sector. The total installed capacity of solar power, including solar photovoltaic and concentrating solar thermal power, is reported to have accelerated substantially from $3 \mathrm{GW}$ in 2004 to $407 \mathrm{GW}$ in 2017 [12]. A steady flow of studies has explored the energy use as well as the carbon emissions throughout the lifetime of solar power systems, which provide valuable knowledge for understanding solar power's energy demand and the associated environmental impacts from a cradle-to-grave manner $[13,14]$.

The net energy values (namely the energy cost induced for per unit of energy output) reported in published works vary in a wide spectrum from highly positive to slightly positive. According to existing published researches, the energy requirements are found to span from $0.1 \mathrm{MJ}$ to $0.9 \mathrm{MJ}$ for per MJ electricity produced by solar thermal power plants $[15,16]$, and from $0.05 \mathrm{MJ}$ to $0.8 \mathrm{MJ}$ for per MJ electricity produced by solar photovoltaic systems $[17,18]$. With regard to carbon emissions induced, Sherwani et al. [17] presented a detailed overview for 16 published life cycle assessments of solar photovoltaic systems, which suggests that carbon emissions associated with different photovoltaic systems located in different areas are in a range from $9 \mathrm{gCO}_{2}$-eq $/ \mathrm{kWh}$ to $280 \mathrm{gCO}_{2}$ eq $/ \mathrm{kWh}$. Lechón et al. [19] reviewed the carbon emissions induced by solar thermal power plants reported in published works, which range in a wide span from $21 \mathrm{gCO}_{2}$-eq $/ \mathrm{kWh}$ to $345 \mathrm{gCO}_{2}$ $\mathrm{eq} / \mathrm{kWh}$ for central tower plants and $10 \mathrm{gCO}_{2}-\mathrm{eq} / \mathrm{kWh}$ to $234 \mathrm{gCO}_{2}-\mathrm{eq} / \mathrm{kWh}$ for parabolic trough plants.

These studies have made significant contributions to figuring out the cumulative energy cost and carbon emissions of solar power systems. It is also worth noticing that non-renewable energy cost is generally not identified from the total energy cost in most of the abovementioned studies. For solar power, the non-renewable energy consumption remains a prime concern since solar power is proposed for reducing fossil fuel consumption. Given this, Chen et al. [20] quantified the nonrenewable energy consumption through the life cycle of a pilot solar power tower system, revealing 
that in order to generate per MJ of electricity, $0.95 \mathrm{MJ}$ of non-renewable energy is needed. This study shows that solar power is not as renewable as generally perceived: generating per unit of energy output from solar power plants requires almost as much as, if not more, non-renewable energy. Nevertheless, similar to previous studies, what accounted in the work by Chen et al. [20] are also limited amounts of primary materials (such as steel and concrete) that make up or for the preparation of the components of the solar power system. In reality, a solar power tower system has multiple components such as solar collectors, tower receivers, heat absorbers, heat reservoirs, turbo-generator system, power distribution equipment, control room and test base [21]. Each one of them requires a chain of inputs in the upstream production processes. Taking solar collectors for instance [22], a large quantity of glass is processed (cutting, edging, grinding, polishing, etc.) to a specific shape of heliostats with the support of machining instruments; silver (or aluminum), ammonia, tartrate, sodium hydroxide solution, formaldehyde and protection paint are required for the production of mirror surface; the foundation of solar collectors requires a whole set of construction engineering (steel structure as the body of bracket, concrete foundation, etc.) and installation engineering services (line laying, pipe erection, heliostat installation, etc.) provided by the construction industry. In the study by Chen et al. [20], however, the solar collectors are converted to a certain amount of glass, steel and concrete contained in mirror, bracket, foundation respectively, which are not even sufficient to represent the inputs of these primary materials in the production chain, not to mention the machinery and service inputs. As a result, simply treating the power plant infrastructure as some primary materials may largely underestimate the non-renewable energy use and emissions induced. As revealed in a work by Lave et al. [23], the truncated inputs may add up to a striking quantity, which may even largely outnumber the direct effects (sometimes by an order of magnitude). Since a component requires different kinds of material, machinery and service inputs that are directly or indirectly connected with the output products of nearly all the economic sectors, each component should be treated separately and put in the context of the macro economy to ensure the integrity of the boundary of the investigated system with that of the economy [24]. In this way the systems-view-based reality for solar power can be obtained.

As a continuation of a previous work [20], this study seeks to further explore the renewable and carbon-neutral characters of solar power under a systems view by studying a pilot solar tower plant in China. A comprehensive review of the methodological development from net energy analysis to non-renewable energy cost analysis is conducted and a quantitative framework for systems evaluation of solar power is proposed. The pilot solar plant is portrayed as an organic system absorbing intermediate inputs as 'nutrients' from the macro economy instead of an isolated system. A complete package of the input items (materials, equipment, services, etc.) in different phases of the solar plant is established. With energy and carbon intensities generated from systems input-output analysis, this work takes a full account of the non-renewable energy cost and carbon emissions ${ }^{1}$ associated with each component, instead of converting the inputs to some primary materials. The non-renewable energy use induced and associated carbon emission are compared to that of coal-fired generation systems in order to reveal the renewability and carbon-neutrality of solar power in contrast to coal-fired power. The rest of this paper's structure is presented as: Section 2 explains the methodology; Section 3 gives a detailed description of the case plant; Section 4 displays the results; Section 5 presents the discussions and scenario analysis; Conclusions are made in the final section.

2. Methodology

2.1. Energy cost: From net energy analysis to non-renewable energy cost analysis

\footnotetext{
${ }^{1}$ The carbon emissions mainly comprise $\mathrm{CO}_{2}, \mathrm{CH}_{4}$ and $\mathrm{N}_{2} \mathrm{O}$. The equivalent relationship for the global warming potential of these three gases is 1:31:210.
} 
In broad sense, energy cost could be regarded as an intuitive extension of the concept of economic cost. The total economic cost required for generating a product involves direct economic costs in terms of purchased raw materials and semi-products, and indirect costs such as depreciation of fixed assets. In analogy, the energy cost of a product is determined by the summed total of the direct energy cost - the onsite energy use, and indirect energy cost - the energy use induced in upstream producing processes to deliver all the material, machinery and service inputs. Since energy use is induced to manufacture, assemble and transport all kinds of goods, it is reasonable to aggregate the energy use induced in the stages of production in order to quantify the total energy cost of a specific product. According to existing literature $[25,26]$, the analytical framework of energy cost firstly appeared in 1969 when Harry Teasley, who was then serving as the packaging manager of the Coco-Cola company, worked with Midwest Research Institute to investigate the resource and environmental impacts of different packaging alternatives for Coca-Cola drinks. A pioneering step of that study was that it broke the tradition of only considering energy resources for economic reasons, and focused on energy cost due to ecological concerns. By tracing the production chain of inputs that form a detailed inventory, the work has quantified the life cycle energy use of beverage cans from extraction to disposal and compared it with that of refillable bottles. A steady flow of subsequent studies [27, 28] has then examined the energy cost of different packaging alternatives by following this manner. This analytical framework for energy cost was then part of the resource and environmental profile analysis (REPA), also a forerunner of the life cycle analysis.

When the concept of energy cost was applied to an energy technology or facility, net energy analysis appeared naturally, comparing the total amount of energy used for supplying the inputs to the energy output of energy production systems or energy savings of energy-conserving technology. For instance, since the large-scale exploitation of fossil energy resources becomes increasingly difficult with time going on, more and more additional energy will be directly and indirectly required to extract coal, crude oil and natural gas from deep underground or from some restricted areas such as offshore places and high mountains. As a result, the net energy gains may gradually decrease and even possibly reach the breakeven point and become negative. Similarly, for energyconservation alternatives such as insulation materials, a certain amount of energy cost is inevitably induced both directly and indirectly to manufacture and transport the materials, which could be compared to the energy savings to see if an energy surplus is achieved by adopting the energysaving technology. The concerns for net energy analysis reached its peak during the energy crisis. The surge of oil prices and the gradually diminishing crude oil reserves impelled people to search for new fuel alternatives. Net energy analysis was thus taken as an effective means to calculate which alternative energy choice could be most energy-efficient as compared to traditional transportation fuels as well as to identify the net energy gains of an energy technology [29, 30]. In 1974, net energy analysis was even written into the federal law (Public Law No. 93-577) of the United States, which regulates that the appraisal proposal of a state-supported energy technology should include the assessment of its potential of net energy production at the commercial scale.

Net energy analysis aims at incorporating all energy inputs supplied by the society and devises an indicator of EROI (energy return on investment) to denote the ratio of energy delivery of a system to the energy used for delivering all the inputs [31,32]. Nevertheless, some concerns are raised towards the way net energy analysis deals with energy investment, as pointed out by Herendeen [33]. First, net energy analysis takes the non-renewable energy resources buried underground as provided free by nature. Therefore, only purchased fuel \& electricity used directly and energy hidden in the materials and services are considered in net energy analysis, while energy contained in the exploited fossil energy resources is excluded. Second, when dealing with the indirect energy cost, net energy analysis considers the inclusive energy cost induced by materials, machinery and service inputs, but does not differentiate the non-renewable energy cost from the inclusive energy use. Net energy analysis, therefore, is incapable of analyzing the non-renewable energy cost of energy systems. 
Since renewable energy alternatives are proposed as substitutes for fossil fuel, what matters most to renewable energy systems is the non-renewable energy cost instead of the inclusive energy cost, which could help identify how much non-renewable energy is saved in contrast to conventional fossil-based energy systems. In this regard, Chen et al. [9] raised the indicator of NEIED to indicate the amount of non-renewable energy consumption by renewable energy systems. Different from EROI, NEIED is defined as the total non-renewable energy cost required directly and indirectly by an energy system divided by the energy output: the direct non-renewable energy cost is taken as the amount of genuine fossil energy resources exploited (taken as zero for renewable energy systems); the indirect non-renewable energy cost refers to the non-renewable energy cost induced by the required materials, equipment and services for the construction, operation and dismantling phases of the specific energy system. As previously mentioned, the larger this indicator, the less renewable the energy system. Meanwhile, for a renewable-based electricity system, since it is raised in an attempt to replace coal-based power (the non-renewability and renewability of coal-based power could be taken as $100 \%$ and $0 \%$ respectively), the non-renewable energy cost avoided for per unit of electricity delivery compared with coal-fired power could be expressed as: $N E I E D_{\text {avoided }}=N E I E D_{\text {coal }}-N E I E D_{\text {renewable }}$, where $N E I E D_{\text {renewable }}$ represents the non-renewable energy investment for one unit of electricity delivery by the renewable-based power generation system; NEIED $D_{\text {coal }}$ is the non-renewable energy investment for one unit of electricity generated by the reference coal-based power system.

The renewability and non-renewability of the renewable-based electricity system could be thus determined as follows:

Renewability $=1-N E I E D_{\text {renewable }} / N E I E D_{\text {coal }}$,

and

Non-renewability $=N E I E D_{\text {renewable }} / N E I E D_{\text {coal }}$.

Generally, the renewability of a renewable energy power generation system in contrast to coalbased power is between zero and $100 \%$. In a sense, the renewability and non-renewability indicators only take different shapes but share the same meaning: the larger the non-renewability of a renewable power generation system, the less the renewability.

Similarly, the carbon emissions avoided for per unit of electricity delivery compared with coalbased power could be expressed as:

$C E_{\text {avoided }}=C E_{\text {coal }}-C E_{\text {renewable }}$,

where $C E_{\text {renewable }}$ represents the carbon emissions generated from one unit of electricity produced by the renewable power generation system; $C E_{\text {coal }}$ is the carbon emissions induced by one unit of electricity output of the reference coal-fired power system.

The carbon-neutrality of solar power could be thus determined as follows:

Carbon-neutrality $=1-C E_{\text {renewable }} / C E_{\text {coal }}$.

The larger the carbon emissions induced, the less carbon-neutral the renewable power generation system.

\subsection{Systems process analysis as a tiered hybrid method}

Systems process analysis, sometimes referred to as the tiered hybrid method which integrates process analysis and systems input-output analysis, is adopted to support the assessment of renewable-based electricity systems. Early studies mainly adopt process analysis in a bottom-up manner when analyzing the energy cost of a product. This bottom-up method tries to incorporate the process flows step by step and is sometimes time-consuming [34]. Since a product is directly or indirectly connected with nearly all economic sectors, the tracing process generally ceases after one or two steps so that the calculations may proceed, just as pointed out by Zhu et al. [35]. As a result, only limited processes are considered, and infinite material and energy flows outside the systems boundary are excluded. Nevertheless, there is no guarantee that the truncated inputs could 
be taken as a negligible amount as compared to the total energy cost, just as noted by Lave et al. [23].

Given the generic flaws rooted in process analysis, energy input-output analysis as a top-down manner integrating the input-output account into an energy balance model appeared in a report by Herendeen [6], in which the energy cost for typical commodities in the United States has been quantified. The input-output account draws a panorama of all the exchange flows between different sectors within the economy, which extends the systems boundary to the whole economy and formulates cross-sectoral linkages between sectors. Following the intuitive principle that inflows of energy use equal the outflows, the balance of energy cost for each economic industry listed in the input-output account is derived: the energy resource exploitation as the direct energy cost plus the energy use hidden in inputs from various sectors as the indirect energy cost equals the energy use hidden in the sectoral output [36]. The energy intensity of goods or services by a sector, namely the energy use induced to produce per unit of sectoral output, can be generated by solving the matrix equations. Subsequent studies have adopted this manner to support net energy analysis of the energy cost of goods produced in different economies in different years [37, 38]. Nevertheless, each coin has two sides. The homogeneity assumption of input-output table implies that energy input-output analysis works efficiently for aggregate products that are well represented by the corresponding commodity sectors, but not for heterogeneous products or atypical technologies, just as noted by Joshi [39]. For instance, renewable energy does not account for an individual sector in most input-output accounts, which makes it difficult to get a panoramic view of its energy cost and environmental emissions.

To integrate the strengths of these two accounting methods but leave out the constraints, a hybrid manner is raised as a possible solution. As summarized by Crawford et al. [40], there exist several kinds of hybrid models in terms of tiered hybrid, path exchange hybrid, matrix augmentation hybrid (also regarded as input-output-based hybrid), and integrated hybrid methods. Regarding path exchange hybrid, matrix augmentation hybrid and integrated hybrid methods, these approaches involve either disaggregation \& modification of input-output matrix or collating process-based data as a matrix form to be strictly connected with input-output matrix, thus suffering from great difficulties in technical manipulation and uncertainty induced by modification of inputoutput data. The tiered hybrid method has the merits of briefness and requires comparatively less additional data as compared to other hybrid models, thus becoming the most commonly applied hybrid method in existing works. The tiered hybrid method was initially suggested by Bullard et al. [41] in 1978 to measure the energy cost of the target product or technology by integrating process analysis with energy input-output analysis. Process analysis makes it feasible to track the production chain to a stage where each input/sub-input is well represented in the corresponding commodity sector. Meanwhile, with the aid of energy input-output analysis, each input item's energy intensity could be quantified, which well reflects the energy use induced in the supply chains of the whole economic network and mitigates the truncation errors that are generic to process analysis caused by the incompleteness of systems boundary.

It needs to be pointed out some practitioners of the tiered hybrid method mainly use energy coefficients generated from environmental-extended input-output analysis to adapt to process analysis, which somewhat deviates from the original intention of Bullard et al. [41]. The environmental-extended input-output analysis builds its foundation on the assignment mapping principle and apportions the energy use to final demand [42]. The energy multiplier, generally referred to as total-consumption multiplier, has its applicability only in the domain of products used as final demand, but not the sector's total outputs. The energy input-output analysis, however, bases its foundation on the conservation mapping and tracks the energy use for the sector's total outputs. The energy intensity matrix derived from energy input-output analysis covers all the sectoral output products, regardless of intermediate or final commodities. Therefore, though the energy intensity matrix derived from energy input-output analysis and that from environmental-extended inputoutput analysis take a similar shape, the domains of definitions are totally different. Since the inputs 
of a production system are generally intermediate inputs, in principle these intermediate inputs should be linked with the energy intensity obtained by the input-output analysis. Afterwards, energy input-output analysis is further extended to systems input-output analysis that is built upon the conservation mapping principle, which serves as an effective means of establishing resource or emission intensity databases for the macro economy [43]. By means of systems process analysis that integrates intensities derived by systems input-output analysis with process analysis, a sheer number of studies have been implemented to assess the energy cost (with non-renewable and renewable energy cost differentiated) and environmental emissions of various types of goods and services, especially atypical products or technologies such as buildings [44], wetlands [45], and coal-fired power plants [24].

\subsection{An integrated accounting framework for renewable energy systems}

Supported by systems process analysis, an integrated accounting framework for solar power systems is established. This framework could be directly transplanted to other renewable energy systems (wind, biomass, hydropower, etc.) as well as fossil fuel power generation plants. It renders a universal means for resource and environmental accounting of general production systems. Detailed procedures are presented as follows:

i. Set up a detailed cost inventory containing all the material, equipment and service inputs throughout the plant's lifetime. The construction stage, operation stage and demolition stage are covered to represent a holistic view of the renewable energy system's performance.

ii. Choose a suitable non-renewable energy and carbon emissions intensity database. Based on systems input-output analysis, energy/carbon emission intensity databases could be generated, which are able to measure the non-renewable energy used (or carbon emissions generated) for manufacturing the products of an economic sector. As a renewable energy system involves multiple inputs that may be sometimes not covered in some macro-scale statistics, it is suggested that an intensity database based on input-output statistics with a lower level of sectoral aggregation should be chosen. For instance, there exist two inputoutput tables for Chinese economy 2007, the 42-sector and 135-sector tables. The 135sector table may be more preferable than the 42 -sector table to be linked with processbased data.

iii. Correspond the input materials, equipment and services to the commodity sectors in the intensity database. The non-renewable energy and carbon emission intensity of each input item could be located in the database.

iv. Perform multiplication of the expenditure of the inputs with corresponding non-renewable energy intensities. The non-renewable energy cost by the renewable energy system could then be yielded by adding the non-renewable energy cost of all the inputs together, which is represented as:

$N E=\sum_{j} N E_{j}=$ Input $_{j} \times \varepsilon_{j}$, in which $N E_{j}$ stands for the non-renewable energy cost of the $j_{t h}$ input; Input ${ }_{j}$ stands for the monetary expenditure of the $j_{t h}$ input; $\varepsilon_{j}$ represents the corresponding non-renewable energy intensity of the $j_{t h}$ input. Similarly, the carbon emissions induced by the solar power system could be represented as:

$C E=\sum_{j} C E_{j}=$ Input $_{j} \times \delta_{j}$,

in which $C E_{j}$ stands for the carbon emissions of the $j_{t h}$ input; $\delta_{j}$ represents the corresponding carbon emission intensity of the $j_{t h}$ input.

v. Calculate the NEIED and the aggregated carbon emission intensity. The NEIED and aggregated carbon intensity of the renewable energy system could be expressed as:

$N E I E D=N E / E_{\text {output }}$, 
and

$C E_{\text {intensity }}=C E / E_{\text {output }}$,

in which $E_{\text {output }}$ represents the energy output of the renewable energy system. Other indicators in terms of $N E I E D_{\text {avoided }}, C E_{\text {saving }}$, renewability and carbon-neutrality could be determined accordingly.

\section{Case study}

\subsection{Case descriptions}

The pilot solar power plant situates at Badaling Town, Yanqing District, Beijing City. The pilot system is the first solar tower plant of megawatt-level in China as well as in Asia, covering 14 hectares of expropriated land for heliostats and 2 hectares of expropriated land for the pilot plant [46]. Under constant support from China's National High-tech Research and Development Program and Beijing Scientific Committee program, the project was launched in 2007 and started operation in August 2012. The pilot plant has a capacity of $1.5 \mathrm{MW}$, with 1800 hours of utilization time per year, and a designed lifetime of 20 years. The annual electricity delivery could be hence calculated as $2.7 \mathrm{GWh}$ and the total electricity yield of the plant throughout its twenty-year lifetime is $54 \mathrm{GWh}$.

As abovementioned, the solar power tower plant contains several parts. Among them the solar collectors' field is acknowledged as the most crucial part, which directly determines the costperformance of the whole plant. The solar collectors' field is paved with 100 heliostats. Each heliostat could automatically rotate around its axis to trace sunlight and reflect the solar radiation to the heaters on the absorber tower. The heaters then convert solar radiation into thermal energy to heat the working fluid (oil).

Given the discontinuity of solar radiation, the heated oil is briefly kept in the energy storage system. The heated oil hereafter flows into the steam generator to produce high-temperature steam, which afterwards enters into the turbine to generate electricity. The turbo-generator is comprised of several subsystems, including heat engine subsystem, electric subsystem, etc. Different from the traditional generation system, the storage system is a key component of the whole solar plant that helps safeguard the stability of power generation [47]. In days of abundant sunlight, excessive solar energy could be stored for power generation at night. This has obviously improved the system efficiency and economic performance. Detailed information for the subsystems is in the feasibility report [46]. The main technical parameters for the pilot solar plant can be seen in Table 1.

Table 1. Main parameters for the pilot solar tower system

\begin{tabular}{ll}
\hline Parameter & Solar tower plant ${ }^{\mathrm{a}}$ \\
\hline Capacity & $1.5 \mathrm{MW}$ \\
Power factor & 0.8 \\
Lifetime & 20 years \\
Annual utilization hours & $1500 \mathrm{~h}$ \\
Averaged annual solar radiation & $5706.6 \mathrm{MJ} / \mathrm{m}^{2}$ \\
Number of heliostats & 100 \\
Mirror reflectivity yearly & 0.75 \\
Receiver efficiency & 0.90 \\
Rated steam flow of the turbine & 8.4 tonne $/ \mathrm{h}$ \\
Rated speed of generator & $1500 \mathrm{r} / \mathrm{min}$ \\
\hline
\end{tabular}

${ }^{\text {a }}$ Refer to Zhao et al. [46]

For test base, the inputs are sorted into power distribution devices, auto-alarm, installation work, and construction engineering. Regarding services, the inputs contain site expropriation, construction management as well as other service fees, which are traditionally ignored in previous studies. For maintenance and operation, the main inputs required include oil that is burned in the 
boiler to heat the steam, and water that is used to cool the working fluid as well as to clean the collectors. Due to the unavailability of data, the non-renewable energy cost and the carbon emissions generated by the transportation and dismantling phases are excluded in this work. As the inputs in these two phases occupy just a meager portion of the whole life chain, the exclusion makes little difference to the final results.

The input items in all the processes are measured in monetary units, based on the first-hand data from the project's feasibility report [46] compiled by the Chinese Academy of Sciences.

\subsection{Databases}

To minimize the truncation errors caused by process analysis, the database built upon systems input-output analysis is used to provide the non-renewable energy and carbon emission intensities of the input items. By using systems input-output accounting that integrates input-output tables into biophysical balance models, a number of intensity databases of energy consumption and carbon emissions have been constructed for the Chinese economy in different years including 2005 [48], 2007 [49] and 2012 [50]. In the current study, as the solar power plant was launched in 2007, the database based on the 135-sector input-output account (including a more detailed classification compared to the 42-sector input-output account) for China economy 2007 was chosen. The energy intensity is measured in $\mathrm{J} / 1 \mathrm{E}+04 \mathrm{CNY}$ and the carbon emission intensity in ton $\mathrm{CO}_{2}$-eq/1E+04 CNY.

With the assistance of the Classification of National Economic Industries (CNEI) [51], each input is matched with the relevant economic sector in the input-output account. Issued by the National Bureau of Statistics in 2011, CNEI sorts the economy delicately into various classes. For instance, turbo-generator is categorized into Section C (Manufacturing industry), Division 38 (Manufacturing of electrical machinery and apparatuses), Group 381 (Manufacture of electrical motors), Class 3811 (Manufacture of turbine-generator sets), which matches Sector 77 (Manufacture of generators) recorded in the 2007 input-output table for China. The economic sector corresponding to each component of the solar plant could be identified in the same way.

Meanwhile, calculating the renewability and carbon-neutrality of the pilot solar plant in contrast to coal-based power requires the reference values for the non-renewable energy cost and carbon emissions of coal-based power. The non-renewable energy used to generate one unit of electricity output has been calculated as $2.90 \mathrm{MJ} / \mathrm{MJ}$ for a most representative coal-fired generation system in China with an installed capacity $2 \times 660 \mathrm{MW}$ in a previous study by Wu et al. [52], which is adopted in this study as the reference NEIED value for China's coal-based power generation plants. The carbon emission intensity of the reference coal-based generation system is then calculated as $275 \mathrm{gCO}_{2}$-eq/MJ $\left(990 \mathrm{gCO}_{2}\right.$-eq/ $\left.\mathrm{kWh}\right)$ by multiplying the $N E I E D$ value with the emission coefficient of coal, the details of which could be found in another previous work [24]. With the reference NEIED and carbon emission intensity for coal-based power obtained, some indicators in terms of $N E I E D_{\text {avoided }}, C E_{\text {avoided }}$, renewability and carbon-neutrality of the pilot solar plant could be accordingly estimated.

\section{Results}

4.1. Component profiles of non-renewable energy cost and carbon emissions of the pilot solar plant

The non-renewable energy cost of the pilot plant is calculated as $3.13 \mathrm{E}+08 \mathrm{MJ}$ in its twentyyear lifespan, details of which are presented in Table 2. A panoramic picture of the non-renewable energy expenditure profile is presented in Fig. 1. Solar collectors' field turns out to be the main inducer of non-renewable energy inputs, contributing nearly a third $(31.50 \%)$ of the total nonrenewable energy inputs. Within the solar collectors' field, the non-renewable energy cost is nearly all attributed to the manufacturing of heliostats. This could be explained by the tremendous energy use that is initiated to manufacture the large number of heliostats. According to the feasibility report, 
the expenses of the one hundred heliostats sum up to 14.25 million CNY, holding a dominating position among the equipment inputs.

Turbo-generator system closely follows the turbo-generator system, accounting for $18.50 \%$ of the total non-renewable energy cost. As shown in Fig. 1, within the turbo-generator system, the heat engine subsystem is responsible for $8.06 \%$ of the plant's total non-renewable energy cost, mainly due to the invested energy-intensive inputs that include the turbo-generator, the deaerator, pipes, insulation paint, etc. As for maintenance and operation, it is the third largest contributor to the total non-renewable energy cost, taking up $15.67 \%$ of the total. The non-renewable energy expenditure associated with maintenance and operation is mainly contributed by the large amount of material usage, namely water and oil. The non-renewable energy use induced to provide the water required in the plant's life cycle takes up $6.32 \%$ of the total while that associated with oil accounts for $9.35 \%$. For the other subsystems of the pilot solar power tower plant, $11.08 \%$ of the non-renewable energy cost is induced by heat exchange system, $11.02 \%$ by services, $7.39 \%$ by test base, and $4.84 \%$ by energy storage system.

From the results, it is seen that over $80 \%$ of the non-renewable energy use occurs during the construction phase of the solar plant. This could be easily understood since solar power is characterized by the low marginal operational costs. The monetary cost of a solar power system mainly resides with plant infrastructure. This further underlines the significance of taking the nonrenewable energy cost induced by plant infrastructure into consideration.

With regard to carbon emissions, the solar plant is estimated to produce $3.42 \mathrm{E}+04$ tonne $\mathrm{CO}_{2}$ eq throughout its life cycle. The contributions of the major parts to carbon emissions induced are somewhat similar to the picture of non-renewable energy cost, as reflected in Fig. 2. Solar collectors' field amounts to $30.63 \%$ of the aggregated carbon emissions of the solar power tower system, followed by turbo-generator system sharing round one-fifth (18.87\%), maintenance and operation sharing around one-eighth $(13.45 \%)$, etc. Besides, the majority of the carbon emissions are associated with the plant's construction stage, sharing over $85 \%$ of the total. 
Table 2. Non-renewable energy cost and carbon emissions induced by the pilot solar power system

\begin{tabular}{|c|c|c|c|c|c|}
\hline Item & Component & $\begin{array}{l}\text { Non-renewable energy } \\
\text { intensity }^{\mathrm{a}}(\mathrm{J} / 10000 \mathrm{CNY})\end{array}$ & $\begin{array}{l}\text { Carbon emissions } \\
\text { intensity }^{\mathrm{a}}(\mathrm{t} / 10000 \mathrm{CNY})\end{array}$ & $\begin{array}{l}\text { Non-renewable } \\
\text { energy use }(\mathrm{J})\end{array}$ & $\begin{array}{l}\text { Carbon } \\
\text { emissions (ton) }\end{array}$ \\
\hline \multicolumn{6}{|c|}{ Solar collectors' field } \\
\hline & Heliostat & $6.68 \mathrm{E}+10$ & $7.07 \mathrm{E}+00$ & $9.52 \mathrm{E}+13$ & $1.01 \mathrm{E}+04$ \\
\hline & Construction engineering & $3.99 \mathrm{E}+10$ & $4.88 \mathrm{E}+00$ & $3.39 \mathrm{E}+12$ & $4.15 \mathrm{E}+02$ \\
\hline Subtotal & & & & $9.86 \mathrm{E}+13$ & $1.05 \mathrm{E}+04$ \\
\hline \multicolumn{6}{|c|}{ Heat exchange system } \\
\hline & Heat absorber & $3.29 \mathrm{E}+10$ & $3.62 \mathrm{E}+00$ & $4.36 \mathrm{E}+12$ & $4.79 \mathrm{E}+02$ \\
\hline & Auxiliary boiler & $3.29 \mathrm{E}+10$ & $3.62 \mathrm{E}+00$ & $4.15 \mathrm{E}+12$ & $4.56 \mathrm{E}+02$ \\
\hline & Fuel supply equipment & $3.56 \mathrm{E}+10$ & $3.89 \mathrm{E}+00$ & $1.72 \mathrm{E}+12$ & $1.88 \mathrm{E}+02$ \\
\hline & Insulation paint & $5.22 \mathrm{E}+10$ & $5.37 \mathrm{E}+00$ & $2.12 \mathrm{E}+12$ & $2.18 \mathrm{E}+02$ \\
\hline & Installation work & $3.99 \mathrm{E}+10$ & $4.88 \mathrm{E}+00$ & $1.82 \mathrm{E}+12$ & $2.22 \mathrm{E}+02$ \\
\hline & Construction engineering & $3.99 \mathrm{E}+10$ & $4.88 \mathrm{E}+00$ & $2.05 \mathrm{E}+13$ & $2.51 \mathrm{E}+03$ \\
\hline \multicolumn{6}{|c|}{ Energy storage system } \\
\hline & Heat reservoir & $4.38 \mathrm{E}+10$ & $4.83 \mathrm{E}+00$ & $1.31 \mathrm{E}+13$ & $1.45 \mathrm{E}+03$ \\
\hline & Installation work & $3.99 \mathrm{E}+10$ & $4.88 \mathrm{E}+00$ & $1.22 \mathrm{E}+12$ & $1.49 \mathrm{E}+02$ \\
\hline & Construction engineering & $3.99 \mathrm{E}+10$ & $4.88 \mathrm{E}+00$ & $7.98 \mathrm{E}+11$ & $9.76 \mathrm{E}+01$ \\
\hline Subtotal & & & & $1.51 \mathrm{E}+13$ & $1.69 \mathrm{E}+03$ \\
\hline \multicolumn{6}{|c|}{ Turbo-generator system } \\
\hline \multicolumn{6}{|c|}{ Heat engine subsystem } \\
\hline & Turbo-generator & $3.27 \mathrm{E}+10$ & $3.54 \mathrm{E}+00$ & $8.07 \mathrm{E}+12$ & $8.74 \mathrm{E}+02$ \\
\hline & By-pass equipment & $3.29 \mathrm{E}+10$ & $3.62 \mathrm{E}+00$ & $5.19 \mathrm{E}+11$ & $5.71 \mathrm{E}+01$ \\
\hline & Deaerator & $3.29 \mathrm{E}+10$ & $3.62 \mathrm{E}+00$ & $1.90 \mathrm{E}+12$ & $2.09 \mathrm{E}+02$ \\
\hline & Other auxiliary equipment & $3.29 \mathrm{E}+10$ & $3.62 \mathrm{E}+00$ & $4.32 \mathrm{E}+12$ & $4.75 \mathrm{E}+02$ \\
\hline & Pipe & $4.38 \mathrm{E}+10$ & $4.83 \mathrm{E}+00$ & $6.94 \mathrm{E}+12$ & $7.65 \mathrm{E}+02$ \\
\hline
\end{tabular}


Insulation paint

Installation work

Chemical water treatment

subsystem

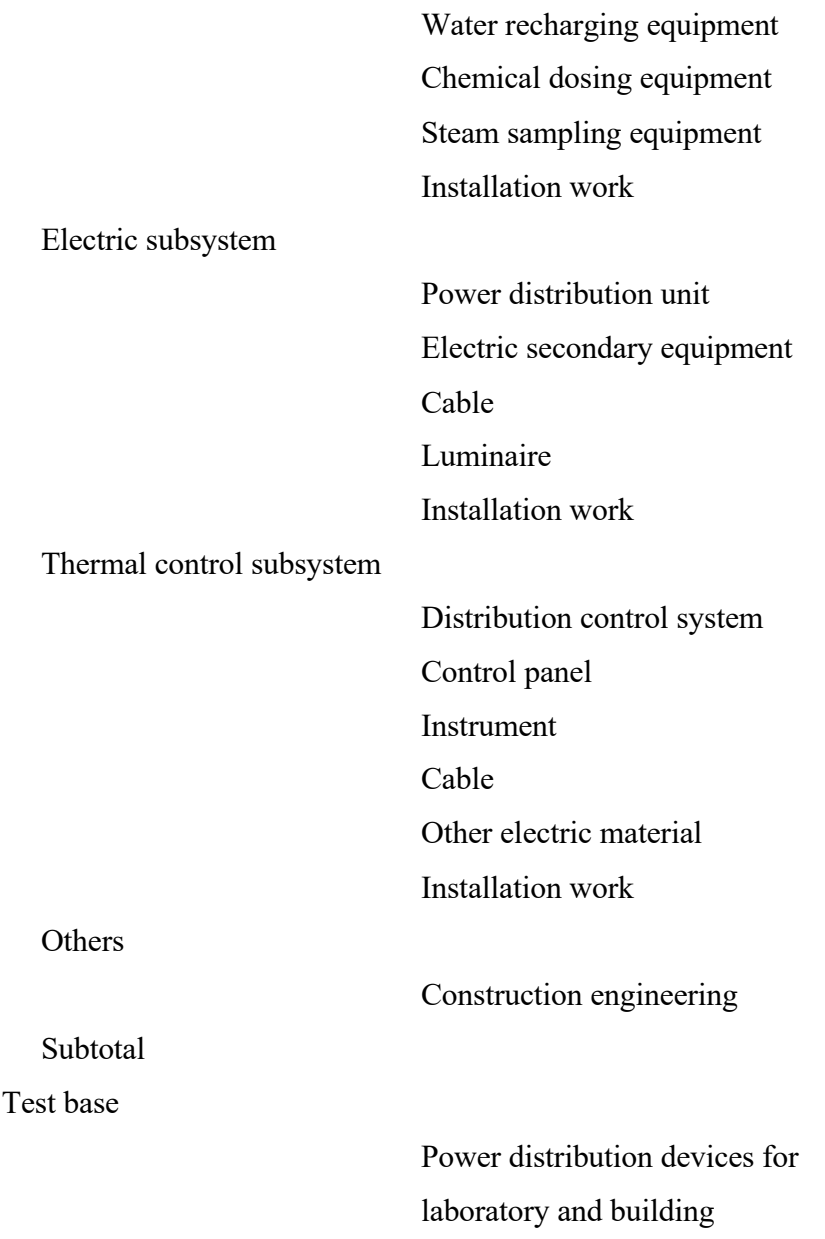

$5.22 \mathrm{E}+10$

$3.99 \mathrm{E}+10$

$5.37 \mathrm{E}+00$

$4.88 \mathrm{E}+00$

$1.04 \mathrm{E}+12$

$2.45 \mathrm{E}+12$

$1.07 \mathrm{E}+02$

$2.99 \mathrm{E}+02$

$3.47 \mathrm{E}+10$
$3.68 \mathrm{E}+10$
$3.47 \mathrm{E}+10$
$3.99 \mathrm{E}+10$

$3.33 \mathrm{E}+10$

$3.33 \mathrm{E}+10$

$3.63 \mathrm{E}+10$

$3.49 \mathrm{E}+10$

$3.99 \mathrm{E}+10$

$2.81 \mathrm{E}+10$

$2.81 \mathrm{E}+10$

$2.81 \mathrm{E}+10$

$3.63 \mathrm{E}+10$

$3.63 \mathrm{E}+10$

$3.99 \mathrm{E}+10$

$3.99 \mathrm{E}+10$

$3.33 \mathrm{E}+10$
$3.79 \mathrm{E}+00$

$4.02 \mathrm{E}+00$

$3.79 \mathrm{E}+00$

$4.88 \mathrm{E}+00$

$3.57 \mathrm{E}+00$

$3.57 \mathrm{E}+00$

$3.84 \mathrm{E}+00$

$3.70 \mathrm{E}+00$

$4.88 \mathrm{E}+00$

$2.99 \mathrm{E}+00$

$2.99 \mathrm{E}+00$

$2.99 \mathrm{E}+00$

$3.84 \mathrm{E}+00$

$3.84 \mathrm{E}+00$

$4.88 \mathrm{E}+00$

$4.88 \mathrm{E}+00$

$3.57 \mathrm{E}+00$

$\begin{array}{ll}1.82 \mathrm{E}+12 & 1.99 \mathrm{E}+02 \\ 1.35 \mathrm{E}+12 & 1.48 \mathrm{E}+02 \\ 1.28 \mathrm{E}+12 & 1.39 \mathrm{E}+02 \\ 7.01 \mathrm{E}+11 & 8.57 \mathrm{E}+01\end{array}$

$5.51 \mathrm{E}+12$

$5.91 \mathrm{E}+02$

$2.07 \mathrm{E}+12 \quad 2.22 \mathrm{E}+02$

$1.96 \mathrm{E}+12 \quad 2.07 \mathrm{E}+02$

$3.49 \mathrm{E}+11 \quad 3.70 \mathrm{E}+01$

$3.58 \mathrm{E}+12 \quad 4.37 \mathrm{E}+02$

$2.80 \mathrm{E}+12 \quad 2.98 \mathrm{E}+02$

$2.95 \mathrm{E}+11 \quad 3.14 \mathrm{E}+01$

$8.71 \mathrm{E}+11 \quad 9.27 \mathrm{E}+01$

$1.68 \mathrm{E}+12 \quad 1.77 \mathrm{E}+02$

$1.00 \mathrm{E}+12 \quad 1.06 \mathrm{E}+02$

$1.39 \mathrm{E}+12 \quad 1.70 \mathrm{E}+02$

$6.01 \mathrm{E}+12 \quad 7.35 \mathrm{E}+02$

$5.79 \mathrm{E}+13 \quad 6.46 \mathrm{E}+03$

$1.61 \mathrm{E}+12 \quad 1.72 \mathrm{E}+02$ 


\begin{tabular}{|c|c|c|c|c|c|}
\hline & Auto-alarm & $2.81 \mathrm{E}+10$ & $2.99 \mathrm{E}+00$ & $4.22 \mathrm{E}+11$ & $4.49 \mathrm{E}+01$ \\
\hline & Installation work & $3.99 \mathrm{E}+10$ & $4.88 \mathrm{E}+00$ & $2.35 \mathrm{E}+11$ & $2.88 \mathrm{E}+01$ \\
\hline & Construction engineering & $3.99 \mathrm{E}+10$ & $4.88 \mathrm{E}+00$ & $2.09 \mathrm{E}+13$ & $2.55 \mathrm{E}+03$ \\
\hline Subtotal & & & & $2.31 \mathrm{E}+13$ & $2.80 \mathrm{E}+03$ \\
\hline \multicolumn{6}{|l|}{ Services } \\
\hline & Site Expropriation fees & $3.99 \mathrm{E}+10$ & $4.88 \mathrm{E}+00$ & $2.94 \mathrm{E}+13$ & $3.59 \mathrm{E}+03$ \\
\hline & Construction management fees & $1.25 \mathrm{E}+10$ & $1.33 \mathrm{E}+00$ & $8.83 \mathrm{E}+11$ & $9.39 \mathrm{E}+01$ \\
\hline & $\begin{array}{l}\text { Technical service fees of } \\
\text { construction }\end{array}$ & $1.25 \mathrm{E}+10$ & $1.33 \mathrm{E}+00$ & $2.03 \mathrm{E}+12$ & $2.16 \mathrm{E}+02$ \\
\hline & Vehicle purchasing fees & $3.00 \mathrm{E}+10$ & $3.26 \mathrm{E}+00$ & $9.46 \mathrm{E}+11$ & $1.03 \mathrm{E}+02$ \\
\hline & Test operation fees & $1.25 \mathrm{E}+10$ & $1.33 \mathrm{E}+00$ & $2.16 \mathrm{E}+11$ & $2.29 \mathrm{E}+01$ \\
\hline & $\begin{array}{l}\text { Heavy-cargo transportation measure } \\
\text { fees }\end{array}$ & $2.58 \mathrm{E}+10$ & $2.45 \mathrm{E}+00$ & $1.03 \mathrm{E}+12$ & $9.80 \mathrm{E}+01$ \\
\hline Subtotal & & & & $3.45 \mathrm{E}+13$ & $4.13 \mathrm{E}+03$ \\
\hline \multicolumn{6}{|c|}{ Maintenance and operation } \\
\hline & Water & $3.37 \mathrm{E}+10$ & $3.60 \mathrm{E}+00$ & $1.98 \mathrm{E}+13$ & $2.11 \mathrm{E}+03$ \\
\hline & Oil & $8.77 \mathrm{E}+10$ & $7.47 \mathrm{E}+00$ & $2.93 \mathrm{E}+13$ & $2.49 \mathrm{E}+03$ \\
\hline Subtotal & & & & $4.90 \mathrm{E}+13$ & $4.61 \mathrm{E}+03$ \\
\hline Total & & & & $3.13 E+14$ & $3.42 \mathrm{E}+04$ \\
\hline
\end{tabular}




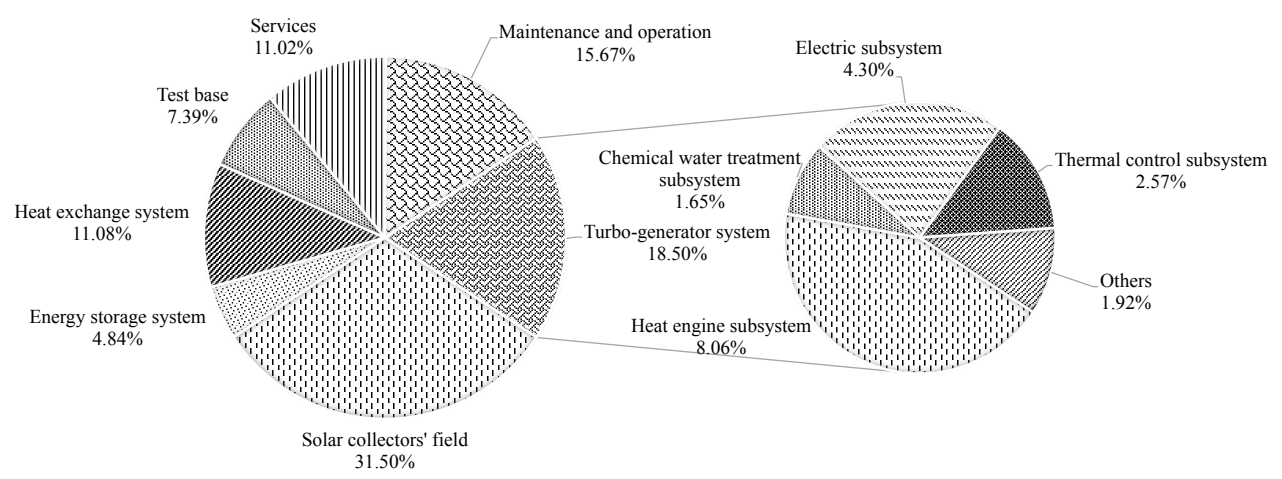

Fig. 1. Non-renewable energy cost of the pilot solar plant



Fig. 2. Carbon emissions induced by the pilot solar plant

\subsection{Sectoral profiles of the non-renewable energy cost and carbon emissions}

Fig. 3 presents the involved sectors' contributions to the non-renewable energy cost through the lifetime of the pilot plant. The Glass sector occupies the first place, contributing to $30.42 \%$ of the total non-renewable energy cost of the pilot plant. As recognized, the Glass sector is a relatively energy-intensive industry. Large quantities of energy products are invested in the processes of material (including silica sand, sodium carbonate, limestone, etc.) pretreatment, melting and heat treatment. The Construction sector closely follows, sharing $29.51 \%$ of the total non-renewable energy expenditure. This high proportion is mainly due to two factors. First, many kinds of services provided by the construction sector, such as foundation construction, pipelines engineering, construction engineering of pumping and water treatment systems, installation engineering of large equipment, and site preparation, are needed by the pilot solar plant. Construction and installation engineering altogether takes up more than one-fourth of the total capital investment. Second, the Construction sector is a highly aggregated sector incorporating various kinds of construction and installation activities, which requires many direct energy products, especially electricity inputs. Besides, large quantities of energy-intensive industrial inputs are required in the construction activities, including cement, steel, aluminum, copper, machinery, which directly or indirectly induce a great deal of fossil fuel usage in the supply chains. As revealed in an existing study [53], the building sector in China is responsible for around one-fourth of the total energy cost, which not only contains the direct energy consumption for providing thermal comfort and normal operation, but also the indirect energy consumption induced by the required services, manufacturing \& transportation of related materials and equipment. 




Fig. 3. Involved sectors' contributions to the total non-renewable energy cost induced

The Petroleum processing sector follows, accounting for around one-tenth $(9.35 \%)$ of the total. One reason is that a large amount of heating oil is required in the operational phase to heat the steam. Besides, as the backbone industry of the national economy, the Petroleum processing sector requires large quantities of electricity and other energy products in the processes of transforming crude oil into various kinds of fuel oil and chemical materials. The non-renewable energy intensity of the petroleum industry is therefore around two or three times as much as that of other involved industries. The rest of the non-renewable energy cost is imputed to the Metal products sector (6.41\%), Water production sector (6.32\%), Boiler and prime mover sector (4.87\%), etc.

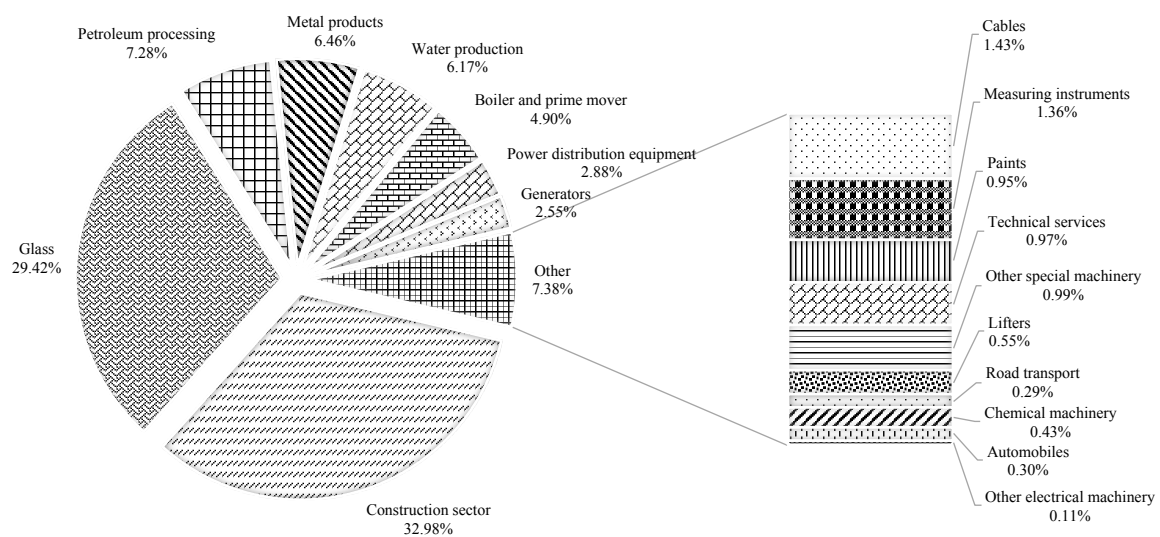

Fig .4. Involved sectors' contributions to the total carbon emissions induced

With regards to carbon emissions induced, the picture resembles that of the non-renewable energy cost profile, as witnessed in Fig. 4. A slight difference is that the Construction sector becomes the largest emitter with a share of around one-third (32.98\%) to the total induced emissions, outpacing the Glass sector that takes up $29.42 \%$ of the total.

\section{Discussions}

5.1. The 'renewable' and 'carbon-neutral' characters of the pilot solar power tower plant

By dividing the aggregate non-renewable energy cost by the electricity yield, the NEIED of the pilot plant is shown as $1.6 \mathrm{MJ} / \mathrm{MJ}(5.76 \mathrm{MJ} / \mathrm{kWh})$. Meanwhile, the carbon emissions induced to produce electricity are shown as $176 \mathrm{gCO}_{2}$-eq/MJ $\left(633 \mathrm{gCO}_{2}\right.$-eq/ $\left.\mathrm{kWh}\right)$. The non-renewable energy cost and carbon emissions calculated for the pilot solar plant are compared to those for coal-based power systems. The energy cost and carbon emissions from life cycle analysis for some coal-fired generation systems in the world regions are presented in Table 3. As shown in Fig. 5, the non- 
renewable energy cost for per unit of energy delivery by the pilot solar power tower system is in magnitude over half of that by the representative coal-fired generation system $(2 \times 660 \mathrm{MW})$ in China [52] as well as that by the coal-based plant (500 MW) in the United Kingdom [54], and 46\% of that by the coal-based plant (360 MW) in the United States [55]. Meanwhile, the carbon emissions for per unit of energy delivery by the pilot solar power system are in magnitude around $60 \%$ of those for the coal-fired generation system $(2 \times 660 \mathrm{MW})$ in China as well as the coal-based plant (500 MW) in the United Kingdom and over $70 \%$ of those for the coal-based plant (360 MW) in the United States, as shown in Fig. 6.

Table 3. Energy cost and carbon emissions of some coal-based power generation systems

\begin{tabular}{lllll}
\hline Reference & Location & Capacity & $\begin{array}{l}\text { Energy cost } \\
(\mathrm{MJ} / \mathrm{kWh})\end{array}$ & $\begin{array}{l}\text { Carbon emissions } \\
\left(\mathrm{gCO}_{2} \text {-eq/kWh }\right)\end{array}$ \\
\hline Wu et al. [24, 52] & China & $2 \times 660 \mathrm{MW}$ & 10.44 & 990 \\
Odeh and Cockerill [54] & United Kingdom & $500 \mathrm{MW}$ & 9.92 & 1022 \\
Spath et al. [55] & United States & $360 \mathrm{MW}$ & 12.41 & 879 \\
\hline
\end{tabular}

As described before, the $2 \times 660 \mathrm{MW}$ power plant is highly representative of China's coal-based generation system. Taking this as a reference, the $N E I E D$ value and carbon emission intensity are respectively $2.9 \mathrm{MJ} / \mathrm{MJ}$ and $275 \mathrm{gCO}_{2}$-eq/MJ $\left(990 \mathrm{gCO}_{2}\right.$-eq $\left./ \mathrm{kWh}\right)$. The non-renewable energy cost avoided $\left(N E I E D_{\text {avoided }}\right)$ and carbon emissions avoided $\left(C E_{\text {avoided }}\right)$ by the pilot solar plant in contrast to coal-based power are thus obtained as $1.3 \mathrm{MJ} / \mathrm{MJ}$ and $99 \mathrm{gCO}_{2}$-eq/MJ, respectively. The renewability and carbon-neutrality of the pilot solar plant in contrast to coal-based power are calculated as $45 \%$ and $36 \%$.

The outcome conveys two messages. The first message is that solar-based power systems are not as renewable and carbon-neutral as generally perceived. The fact that the NEIED value is larger than one suggests that the non-renewable energy investment of the pilot plant has in magnitude exceeded the electricity output, illustrating that solar power is far from being free of depleting nonrenewable energy resources. Besides, the associated carbon emissions by the pilot plant also reach a surprisingly high volume, approximately half of those by coal-based power. These results support the argument that it is not feasible for solar-based power systems to be $100 \%$ renewable and carbonneutral. The perspective obtained under a systems view counters the local-view-based picture that only includes the onsite information but leaves out the offsite information. Under a local view, the intuitive understanding is that solar-based power systems are totally renewable and carbon-neutral since there is little fossil energy consumption nor carbon emissions occurring in the onsite field. Under a systems view, however, the interaction between domains inside and outside the systems boundary is well considered. The solar power plant is portrayed as a production system fed by various kinds of goods and services coming from a wide spectrum of economic sectors; these goods and services are the output of the economy with primary non-renewable energy \& other ecological resources as essential exogenous environmental support and carbon \& other types of emissions as environmental impact. Therefore, though the onsite energy cost and carbon emissions may be marginal, a large quantity of non-renewable energy use and carbon emissions are induced elsewhere in the supply chains of the economy to generate the required goods and services.

The second message is that although considerable amounts of non-renewable energy use and carbon emissions are induced by the pilot solar plant, solar power still tends towards a renewable and carbon-neutral option as compared to coal-based power. The numerical values of renewability (45\%) and carbon-neutrality (36\%) indicate that the induced non-renewable energy use and carbon emissions for per unit of electricity output could plummet to half when the pilot solar power plant is adopted as an alternative to replace fossil-fueled power. Besides, the indicator of $N E I E D_{\text {saving }}$ shows that, for per unit of electricity output, around 1.3 times equivalent units of non-renewable energy resources could be saved by the pilot solar power system in contrast to typical coal-based 
power generation systems. This suggests that solar power may still appear to be a promising alternative for electricity supply and mitigation of fossil-related emissions.

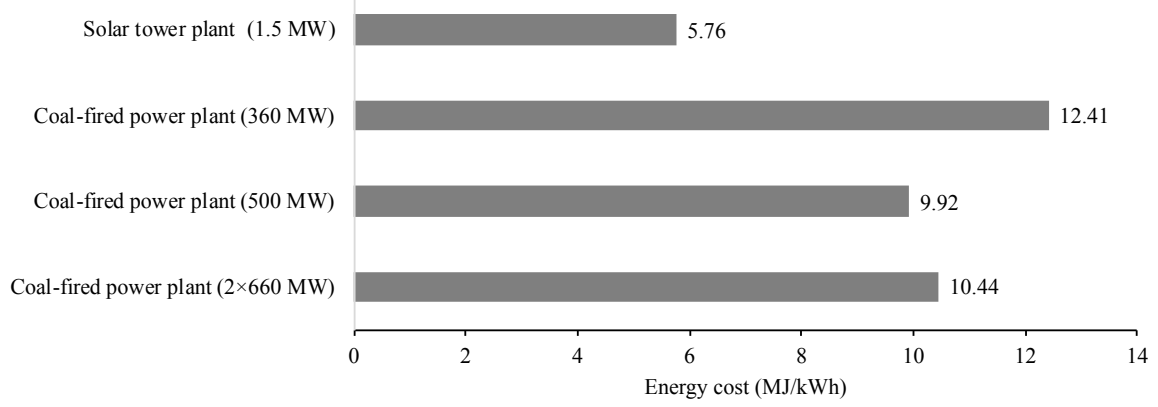

Fig. 5. Comparison of non-renewable energy use by the pilot solar plant to that by coal-fired power plants

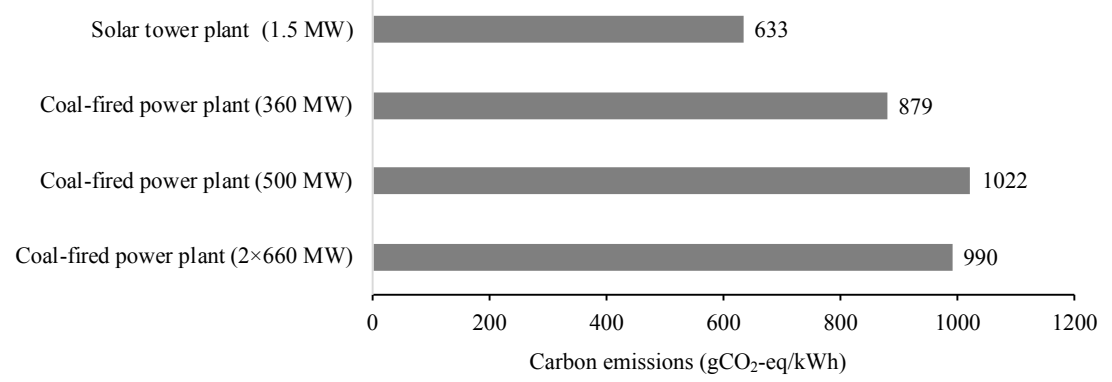

Fig. 6. Comparison of carbon emissions by the pilot solar plant to those by coal-fired power plants

\subsection{Comparison with solar power tower systems reported in previous studies}

Table 4 lists the results for some solar tower plants discussed in existing studies. The nonrenewable energy cost for per unit of electricity output in this study is in magnitude 1.7 times as much as that in the previous work [20], and the carbon emissions induced turn out to be over three times larger than those in the previous work. An underestimation of non-renewable energy expenditure and carbon emissions is revealed for the previous study. The primary reason is that in the previous study, the energy cost is regarded as the energy used for manufacturing the raw materials that constitute the components, such as steel, copper, glass, concrete and brick. This scarcely reflects any information of the manufacturing process and excludes the large number of intermediate inputs invested in the supply chain. In this work, the components of the solar plant are inclusively traced back to a certain degree at which the inputs could be well included as typical products in the economy, instead of only treating the plant's infrastructure as the raw materials. By applying the intensity dataset derived from systems input-output accounting, the energy use in the whole economic network for producing each input is determined. Another reason is that the databases adopted in the two studies are based on different years. In the previous study, the intensity database is corresponded to the year 1992. While in the present research, the database is corresponded to the 2007 input-output table, which could be well adapted to the solar power plant under investigation that has been launched in 2007. The industrial structure as well as technology has experienced changes in the last two decades, which inevitably results in varied energy and carbon emissions intensities for the associated products. In future studies, the impact of industrial structure change on the intensity dataset derived from input-output accounts could be analyzed. Moreover, different accounting systems of input-output tables may also cause uncertainty and deviation in results. In the previous study, the intensity dataset is built upon the 1992 input-output account for China's economy, which belongs to the material product system (MPS) and follows the balance of material product flows in the compilation process. The material product system 
classifies the national economic activities into material production domain and non-material product domain: only those activities that generate material products or provide labor services for material production could be treated as producing activities; social products are deemed as the outcome of material production and represent the wealth of a nation. In this work, the intensity database is built upon the 2007 input-output account for China, which falls into the system of national accounts (SNA) and follows the balance of economic flows. The system of national accounts is built upon the national income account and treats both material and non-material production as producing activities: the intrinsic ideology is that the essence of production does not rest with providing material products or not, but rests with whether the production activities create new economic utility or not. As seen, due to the different inherent ideologies, the input-output account of an economy based on the material product system may be obviously differing from that based on the system of national accounts even for the same year. Hence, the intensity databases generated from input-output tables under different accounting systems may also show deviation. Meanwhile, since input-output tables have the homogenous assumption for sectoral products, the aggregation level of the input-output tables may have an influence on the uncertainty of the results. As previously mentioned, the intensity database adopted in this work is built on China's 135 -sector input-output account, which is by far one of the most comprehensive and detailed input-output tables for China's economy and thus cuts down the uncertainty in the results.

In comparison to other solar power tower plants, the non-renewable energy cost obtained in this study is two times as much as that for the $17 \mathrm{MW}$ central tower system in Spain that is reported in the work by Lechón et al. [19], and higher by over one-order of magnitude than that for the United States' 115 MW solar plant that is reported in the work by Whitaker et al. [56]. As for the carbon emission induced by per unit of electricity output, the result in this study is over three times larger than that for the $17 \mathrm{MW}$ solar tower plant in Spain [19] as well as that for the 5MW solar tower plant in Japan [57], and higher than that for the United States' 115 MW solar tower plant [56] by an order of magnitude. In these works, it is also witnessed that the inputs are regarded as some raw materials, thus resulting in the leakage concern as mentioned above. This has further consolidated the necessity of re-evaluating the renewability of solar power tower systems in different nations. Apart from the leakage concern, other factors also hold accountable for the deviation in the results. One is that the energy cost for a unit of electricity output is correlated with the plant scale. With the increase of the installed capacity, the resource use and emissions for per unit of electricity delivered are supposed to slide to a certain extent. In addition, the databases for different areas also make a difference. As these solar tower power plants are located in different countries, the energy (or carbon emission) intensity varies for the same type of product manufactured in different regions.

Table 4. Energy cost and carbon emissions for solar power tower plants in existing studies

\begin{tabular}{lllll}
\hline Reference & Location & Capacity & $\begin{array}{l}\text { Energy cost } \\
(\mathrm{MJ} / \mathrm{kWh})\end{array}$ & $\begin{array}{l}\text { Carbon emissions } \\
\left(\mathrm{gCO}_{2} \text {-eq/kWh }\right)\end{array}$ \\
\hline Chen et al. [20] & China & $1.5 \mathrm{MW}$ & 3.43 & 140 \\
Whitaker et al. [56] & United States & $115 \mathrm{MW}$ & 0.49 & 37 \\
Lechón et al. [19] & Spain & $17 \mathrm{MW}$ & 2.79 & 203 \\
Uchiyama [57] & Japan & $5 \mathrm{MW}$ & N/A & 213 \\
\hline
\end{tabular}

\subsection{Comparison with solar photovoltaic systems reported in previous studies}

Table 5 lists the energy use and carbon emissions by some solar photovoltaic systems reported in previous studies. The energy cost of the $1.5 \mathrm{MW}$ pilot tower plant is in magnitude around two times that of the $2.7 \mathrm{~kW}$ photovoltaic system in Singapore in Kannan et al.'s study [58], 4.3 times that of the United States' $33 \mathrm{~kW}$ multi-crystalline system in Pacca et al.'s study [59], and over seven times that of the $100 \mathrm{MW}$ high-concentration photovoltaic system in China in Nishimura et al.'s study [60]. As for the carbon emission induced by per unit of energy output, the result obtained 
for the 1.5 MW pilot solar tower system is in magnitude around three times that of the $2.7 \mathrm{~kW}$ photovoltaic system in Singapore [58], six times as much as that of the $3 \mathrm{~kW}$ photovoltaic system in Greece [61], and more than eight times that of the $33 \mathrm{~kW}$ photovoltaic system in the United States [59].

Table 5. Energy use and carbon emissions by solar photovoltaic systems reported in previous works

\begin{tabular}{lllll}
\hline Reference & Location & Capacity & $\begin{array}{l}\text { Energy cost } \\
(\mathrm{MJ} / \mathrm{kWh})\end{array}$ & $\begin{array}{l}\text { Carbon emissions } \\
\left(\mathrm{gCO}_{2} \text {-eq } / \mathrm{kWh}\right)\end{array}$ \\
\hline Kannan et al. [58] & Singapore & $2.7 \mathrm{~kW}$ & 2.91 & 217 \\
Pacca et al. [59] & United States & $33 \mathrm{~kW}$ & 1.33 & 72.4 \\
Nishimura et al. [60] & China & $100 \mathrm{MW}$ & 0.78 & $\mathrm{~N} / \mathrm{A}$ \\
Tripanagnostopoulos et al. [61] & Greece & $3 \mathrm{~kW}$ & $\mathrm{~N} / \mathrm{A}$ & 104 \\
\hline
\end{tabular}

Meanwhile, as can be seen, the energy cost as well as carbon emission induced for per unit of energy output by the pilot solar plant is somewhat larger than that by solar photovoltaic systems. This does not mean that solar thermal power plants are absolutely superior to solar photovoltaic systems. In existing studies, solar photovoltaic systems' infrastructure is generally treated are some primary materials that constitute the photovoltaic module or balance of system (BOS) components, which may at some degree lead to the underestimation of the energy expenditure and associated emissions. Further evaluation is required for assessing the renewability of solar photovoltaic systems by inclusively treating the different components as products of the economy.

\subsection{Comparison with wind power}

Wind power as another flourishing renewable alternative bears a resemblance to solar power in that these two renewable options are both characterized by abundant energy sources as well as intermittency in electricity delivery and receive a number of policy incentives including feed-in tariff and special subsidies from the government. Therefore, the results in the present study are compared to the environmental performance of wind power. Chen et al. [9] has reviewed the nonrenewable energy consumption and carbon emissions from per unit of electricity production by some wind farms reported in existing studies [62-64], as listed in Table 6. As shown, the nonrenewable energy consumption ranges from $0.05 \mathrm{MJ} / \mathrm{kWh}$ to $0.54 \mathrm{MJ} / \mathrm{kWh}$, and the carbon emissions induced are between $7.2 \mathrm{~g} \mathrm{CO}_{2}$-eq/ $\mathrm{kWh}$ to $442.8 \mathrm{~g} \mathrm{CO}_{2}$-eq/ $\mathrm{kWh}$. Therefore, the nonrenewable energy cost of the pilot solar plant is higher than that of wind farms by approximately an order of magnitude, and the carbon emissions are also obviously larger in volume than those of wind farms. From the perspective of non-renewable resource preservation and abatement of carbon emissions, wind power may have some advantages over solar power tower-based electricity.

Table 6. Energy consumption and carbon emissions of the wind farms reported in previous studies

\begin{tabular}{lllll}
\hline Reference & Location & Capacity & $\begin{array}{l}\text { Energy cost } \\
(\mathrm{MJ} / \mathrm{kWh})\end{array}$ & $\begin{array}{l}\text { Carbon emissions } \\
\left(\mathrm{gCO}_{2} \text {-eq } / \mathrm{kWh}\right)\end{array}$ \\
\hline Lenzen and Munksgaard [62] & Worldwide & N/A & $0.05 \sim 0.54$ & $28.8 \sim 442.8$ \\
Chen et al. [9] & China & $1.25 \mathrm{MW}$ & 0.17 & 7.6 \\
Ardente et al. [63] & Italy & $660 \mathrm{~kW}$ & $0.14 \sim 0.25$ & $7.2 \sim 14.4$ \\
Crawford [64] & Australia & $3 \mathrm{MW}$ & 0.15 & 108 \\
\hline
\end{tabular}

\subsection{Scenario analysis}

Within the thirteenth five-year plan for the development of renewable energy [65], it is planned that by the end of 2020 solar thermal power and solar photovoltaic power should respectively achieve a total capacity of $5000 \mathrm{MW}$ and $105 \mathrm{GW}$, while the electricity production per year is supposed to reach an amount of $20 \mathrm{TWh}$ and $124.5 \mathrm{TWh}$, respectively. The pilot 1.5 MW solar plant situated in Beijing, as the first megawatt-scale solar power tower plant and a representative solar thermal electricity generation system, was highlighted in the document for contributing to the 
accumulation of valuable experience of capacity expansion and commercial deployment of solar power, which could be thus taken as a reference system. Assuming that the non-renewable energy cost (as well as carbon emissions) for per unit of electricity production by solar thermal systems is equal to that by solar photovoltaic systems, the results calculated for the pilot solar plant are applied to giving a rough estimation of the annual non-renewable energy use avoided and carbon emissions avoided by solar-based power generation as compared to coal-based power production under the 2020 scenario. As previously calculated, the non-renewable energy cost avoided and carbon emissions avoided by the pilot solar power system in contrast to coal-based power generation for a unit of energy output are $1.3 \mathrm{MJ} / \mathrm{MJ}$ and $99 \mathrm{gCO}_{2}$-eq/MJ, respectively. The annual non-renewable energy cost avoided and carbon emissions avoided by solar-based electricity generation in China under the 2020 scenario are respectively estimated to be $6.76 \mathrm{E}+11 \mathrm{MJ}$ (23.07 million tons of coal equivalent) and 51.50 million tons $\mathrm{CO}_{2}$-eq.

Fig. 7 presents the annual energy consumption of several Chinese regions in 2015 provided by China Energy Statistical Yearbook [66], measured in tons of standard coal equivalent. As shown, the annual non-renewable energy cost avoided by solar power generation in contrast to coal-based power production is estimated to be in magnitude up to one-third of the direct energy consumption in Beijing, one-fifth of that in Shanghai, and around one-eighth of that in Shanxi as well as that in Hubei.

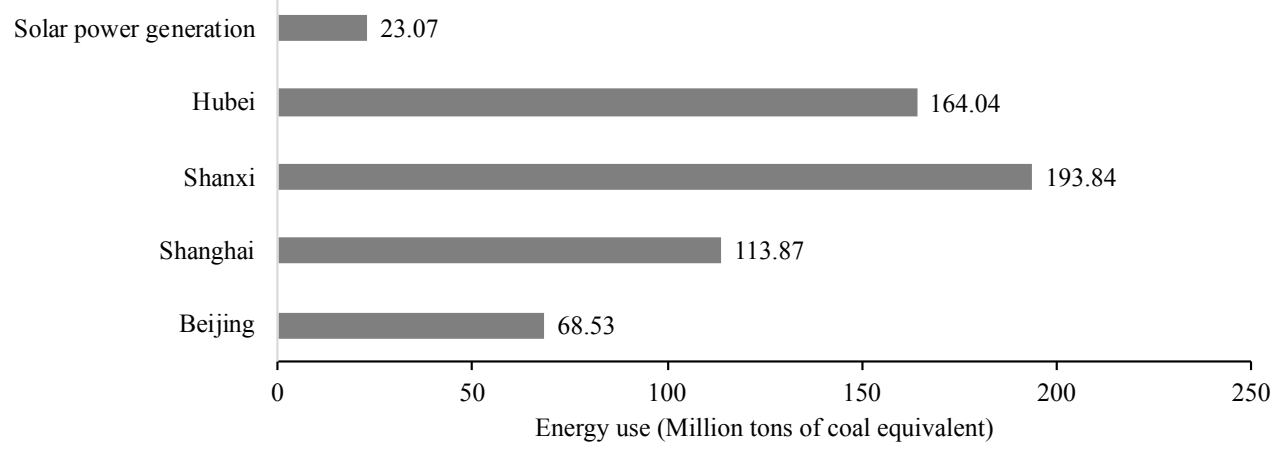

Fig. 7. Comparison of the annual energy use of some regions with that avoided by solar-based power generation in China under the 2020 scenario

Fig. 8 illustrates the direct energy consumption of some industries in 2015 given by the China Energy Statistical Yearbook [66]. As demonstrated, the non-renewable energy cost avoided per year by solar power generation is in magnitude over $70 \%$ of the direct energy consumption by Automobiles sector, around half of that by the Extraction of Petroleum and Natural Gas sector as well as that by the Metal Products sector, nearly $60 \%$ of that by the Paper products sector, and around $30 \%$ of that by the Construction sector.

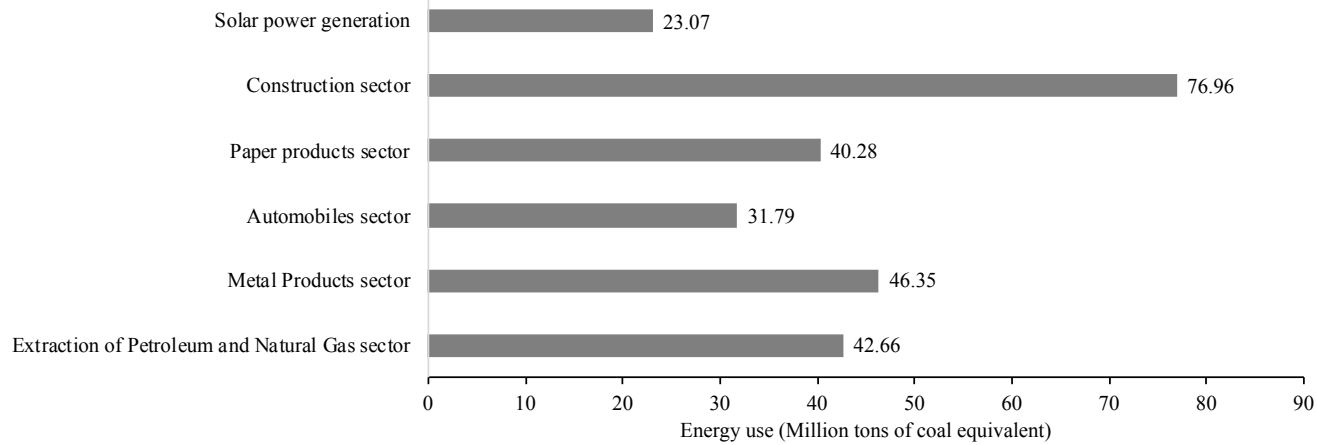

Fig. 8. Comparison of the annual energy use of some industries with that avoided by solar power generation in China under the 2020 scenario 
With regard to carbon emissions, Fig. 9 presents the annual carbon emissions of some world regions in terms of New York [67], London [67], Xiamen [68] and Shenyang [69]. As shown, under the 2020 scenario, the annual carbon emissions avoided by solar power generation in China are around $60 \%$ of the direct emissions of New York in the year 2005, 77\% of those by London in 2003, nearly equivalent to those by Shenyang in 2007, and around two times as much as those by Xiamen in 2007.

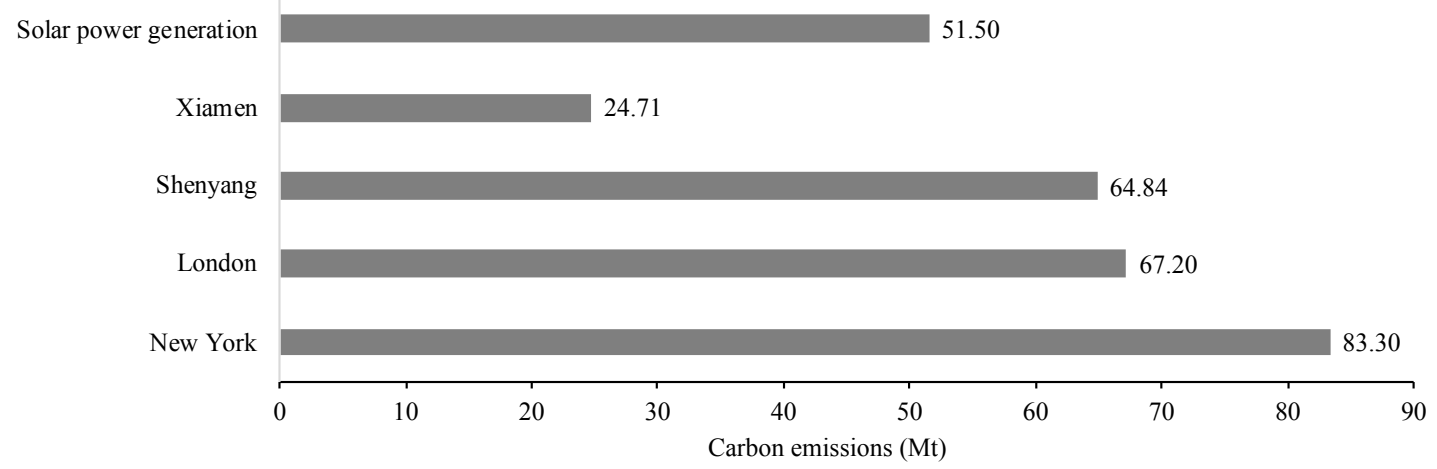

Fig. 9. Comparison of some regions' direct emissions with emissions avoided by solar-based power generation in China under the 2020 scenario

\section{Conclusions}

This study aims to take a systems view to quantitatively address the concern on whether solar power is renewable and carbon-neutral by the case of a typical pilot solar plant in China. An evaluation framework for non-renewable energy cost and carbon emissions by renewable-based electricity is developed under the support of systems process analysis that unites systems inputoutput analysis and process-based analysis. A package of indicators in terms of NEIED avoided, $C E_{\text {avoided, }}$ renewability, as well as carbon-neutrality are devised to characterize the renewable and carbon-neutral characters of solar power.

This study revealed the intensive non-renewable energy investment and carbon emissions induced by solar power. The NEIED calculated for the pilot plant suggests that the non-renewable energy invested is 1.6 times larger than the amount of electricity output, and the carbon emissions are obtained as $176 \mathrm{gCO}_{2}$-eq/MJ. The outcome obtained under the systems view differs from the local-realism-based picture that treats solar-based power systems as $100 \%$ renewable and carbonneutral. Under the systems view, the solar-based power system is identified not as an isolated system as in the local-realism-based picture but a subdomain absorbing 'nutrients' (intermediate inputs) from the domain of the economy that is supported by external non-renewable energy resources, thus not being able to refrain from non-renewable energy cost and the associated emissions. Meanwhile, the results in the present study are several times larger than those generated in some existing life cycle studies, since the inputs of the solar power system are traced in great detail to be well-linked with the economy instead of being converted to some primary materials, thus properly avoiding the uncertainty that may be induced by truncated inputs. This also provides supporting evidence for existing arguments holding that the truncated inputs induced by arbitrary selection of systems boundary may amount to a significant amount and should be not taken as negligible.

Though solar power may be not as renewable as widely perceived, this study pointed out that solar power still serves as a promising substitute for coal-fired electricity generation. The nonrenewable energy cost and carbon emission induced for a unit of electricity delivery by the pilot solar power system are in magnitude respectively $55 \%$ and $64 \%$ of that by coal-fired electricity generation. The NEIED avoided calculated implies that a saving of 1.3 times equivalent units of non- 
renewable energy resources could be achieved by the pilot solar power system as compared to coalbased power generation. Under the 2020 scenario, the annual non-renewable energy cost avoided by solar power as compared to coal-based power production is estimated as 23.07 million tons of coal equivalent, which are one-third of Beijing's direct energy consumption. Besides, the annual carbon emissions avoided are roughly estimated as 51.50 million tons $\mathrm{CO}_{2}$-eq, which are approximately $60 \%$ of New York's carbon emissions. In particular, considering that the solar plant under investigation is still on a pilot scale, improvement of technology, expansion of installed capacity, decline of component cost may further reduce the non-renewable energy cost and carbon emissions of solar-based power systems, thus making it more capable in the future to replace coalbased power. The systems-view-based evaluation framework and the package of indicators raised in this study are applicable to all kinds of renewable-based electricity systems, which may be supportive of complementing the local-realism-based picture and providing a new perspective of the 'renewable' and 'carbon-neutral' characters of renewable-based electricity.

\section{Acknowledgement}

This work is supported by the National Natural Science Foundation of China (Grant Nos. 71904003 and 51879002).

\section{References}

[1] Heard BP, Brook BW, Wigley TML, Bradshaw CJA. Burden of proof: A comprehensive review of the feasibility of $100 \%$ renewable-electricity systems. Renewable and Sustainable Energy Reviews. 2017;76:1122-33.

[2] Harjanne A, Korhonen JM. Abandoning the concept of renewable energy. Energy Policy. 2019;127:330-40.

[3] Klass D, Cleveland C. Encyclopaedia of Energy 2004; vol. 1. Search PubMed.193-212.

[4] IEA. IEA FAQ on Renewable energy. International Energy Agency; 2018.

[5] Eurostat. Renewable energy statistics, Eurostat statistics explained. Web resource. 2018.

[6] Herendeen R. An energy input-output matrix for the United States, 1963: User's guide. University of Illinois; 1973.

[7] Pang M, Zhang L, Bahaj AS, Xu K, Hao Y, Wang C. Small hydropower development in Tibet: Insight from a survey in Nagqu Prefecture. Renewable and Sustainable Energy Reviews. 2018;81:3032-40.

[8] Zhang S, Zhao X, Andrews-Speed P, He Y. The development trajectories of wind power and solar PV power in China: A comparison and policy recommendations. Renewable and Sustainable Energy Reviews. 2013;26:322-31.

[9] Chen GQ, Yang Q, Zhao YH. Renewability of wind power in China: A case study of nonrenewable energy cost and greenhouse gas emission by a plant in Guangxi. Renewable \& Sustainable Energy Reviews. 2011;15:2322-9.

[10] Yang Q, Chen GQ. Nonrenewable energy cost of corn-ethanol in China. Energy Policy. 2012;41:340-7.

[11] Yang Q, Chen GQ. Greenhouse gas emissions of corn-ethanol production in China. Ecological Modelling. 2013;252:176-84.

[12] REN21. Renewables 2018 Global Status Report. Renewable Energy Policy Network for the 21 st century; 2018.

[13] Stoppato A. Life cycle assessment of photovoltaic electricity generation. Energy. 2008;33:224-32.

[14] Piemonte V, Falco MD, Tarquini P, Giaconia A. Life Cycle Assessment of a high temperature molten salt concentrated solar power plant. Solar Energy. 2011;85:1101-8. 
[15] Burkhardt JJ, Heath GA, Turchi CS. Life cycle assessment of a parabolic trough concentrating solar power plant and the impacts of key design alternatives. Environmental science \& technology. 2011;45:2457-64.

[16] Lamnatou C, Chemisana D. Concentrating solar systems: Life Cycle Assessment (LCA) and environmental issues. Renewable and Sustainable Energy Reviews. 2017;78:916-32.

[17] Sherwani AF, Usmani JA, Varun. Life cycle assessment of solar PV based electricity generation systems: A review. Renewable and Sustainable Energy Reviews. 2010;14:540-4.

[18] Ludin NA, Mustafa NI, Hanafiah MM, Ibrahim MA, Asri Mat Teridi M, Sepeai S, et al. Prospects of life cycle assessment of renewable energy from solar photovoltaic technologies: A review. Renewable and Sustainable Energy Reviews. 2018;96:11-28.

[19] Lechón Y, de la Rúa C, Sáez R. Life cycle environmental impacts of electricity production by solar thermal power plants in Spain. Journal of Solar Energy Engineering. 2008;130:021012-7.

[20] Chen GQ, Yang Q, Zhao YH, Wang ZF. Nonrenewable energy cost and greenhouse gas emissions of a 1.5 MW solar power tower plant in China. Renewable \& Sustainable Energy Reviews. 2011;15:1961-7.

[21] He Y-L, Qiu Y, Wang K, Yuan F, Wang W-Q, Li M-J, et al. Perspective of concentrating solar power. Energy. 2020;198:117373.

[22] Li G, Xuan Q, Akram MW, Golizadeh Akhlaghi Y, Liu H, Shittu S. Building integrated solar concentrating systems: A review. Applied Energy. 2020;260:114288.

[23] Lave LB, Cobas-Flores E, Hendrickson CT, McMichael FC. Using input-output analysis to estimate economy-wide discharges. Environmental Science \& Technology. 1995;29:420A-6A. [24] Wu XD, Guo JL, Chen GQ. The striking amount of carbon emissions by the construction stage of coal-fired power generation system in China. Energy Policy. 2018;117:358-69.

[25] Hunt R. LCA — How it came about. Int J Life Cycle Assess. 1996;1.

[26] Boustead I. LCA — how it came about. Int J LCA. 1996;1:147-50.

[27] Franklin WE, Hunt RG. Environmental impacts of polystyrene foam and molded pulp meat trays: A Summary Report: Midwest Research Institute; 1972.

[28] Hannon BM. Bottles cans energy. Environ Sci Policy Sustain Dev. 1972;14:11-21.

[29] Herendeen RA, Kary T, Rebitzer J. Energy analysis of the solar power satellite. Sci New Ser. 1979;205:451-4.

[30] Chambers RS, Herendeen RA, Joyce JJ, Penner PS. Gasohol: Does it or doesn't it produce positive net energy? Sci New Ser. 1979;206:789-95.

[31] Raugei M, Fullana-i-Palmer P, Fthenakis V. The energy return on energy investment (EROI) of photovoltaics: Methodology and comparisons with fossil fuel life cycles. Energy Policy. 2012;45:576-82.

[32] Bhandari KP, Collier JM, Ellingson RJ, Apul DS. Energy payback time (EPBT) and energy return on energy invested (EROI) of solar photovoltaic systems: A systematic review and metaanalysis. Renewable and Sustainable Energy Reviews. 2015;47:133-41.

[33] Herendeen RA. Net energy analysis: Concepts and methods. In: Cleveland CJ, editor. Encyclopedia of Energy. New York: Elsevier; 2004. p. 283-9.

[34] Wang C, Zhang L, Chang Y, Pang M. Biomass direct-fired power generation system in China: An integrated energy, GHG emissions, and economic evaluation for Salix. Energy Policy. 2015;84:155-65.

[35] Zhu Y, Liang J, Yang Q, Zhou H, Peng K. Water use of a biomass direct-combustion power generation system in China: A combination of life cycle assessment and water footprint analysis. Renewable and Sustainable Energy Reviews. 2019;115:109396.

[36] Bullard CW, Herendeen RA. The energy cost of goods and services. Energy Policy. 1975;3:268-78.

[37] Herendeen RA. Input-output techniques and energy cost of commodities. Energy Policy. 1978;6:162-5. 
[38] Denton RV. The energy cost of goods and services in the Federal Republic of Germany. Energy Policy. 1975;3:279-84.

[39] Joshi S. Product environmental life-cycle assessment using input-output techniques. Journal of Industrial Ecology. 1999;3:95-120.

[40] Crawford RH, Bontinck P-A, Stephan A, Wiedmann T, Yu M. Hybrid life cycle inventory methods - A review. Journal of Cleaner Production. 2018;172:1273-88.

[41] Bullard CW, Penner PS, Pilati DA. Net energy analysis: Handbook for combining process and input-output analysis. Resources and energy. 1978;1:267-313.

[42] Chen GQ, Wu XF. Energy overview for globalized world economy: Source, supply chain and sink. Renewable and Sustainable Energy Reviews. 2017;69:735-49.

[43] Wu XD, Guo JL, Li C, Chen GQ, Ji X. Carbon emissions embodied in the global supply chain: Intermediate and final trade imbalances. Science of The Total Environment. 2019:134670.

[44] Han MY, Chen GQ, Shao L, Li JS, Alsaedi A, Ahmad B, et al. Embodied energy

consumption of building construction engineering: Case study in E-town, Beijing. Energy and Buildings. 2013;64:62-72.

[45] Shao L, Wu Z, Zeng L, Chen ZM, Zhou Y, Chen GQ. Embodied energy assessment for ecological wastewater treatment by a constructed wetland. Ecological Modelling. 2013;252:63-

71.

[46] Zhao YH. Feasibility report of Dahan solar tower project. Beijing: China Huadian

Corporation; 2008.

[47] Tschopp D, Tian Z, Berberich M, Fan J, Perers B, Furbo S. Large-scale solar thermal systems in leading countries: A review and comparative study of Denmark, China, Germany and Austria. Applied Energy. 2020;270:114997.

[48] Chen ZM, Chen GQ, Zhou JB, Jiang MM, Chen B. Ecological input-output modeling for embodied resources and emissions in Chinese economy 2005. Communications in Nonlinear Science and Numerical Simulation. 2010;15:1942-65.

[49] Chen GQ, Chen ZM. Carbon emissions and resources use by Chinese economy 2007: A 135sector inventory and input-output embodiment. Communications in Nonlinear Science and Numerical Simulation. 2010;15:3647-732.

[50] Wu XF, Chen GQ. Energy use by Chinese economy: A systems cross-scale input-output analysis. Energy Policy. 2017;108:81-90.

[51] CNEI. Classification of National Economic Industries. Beijing: National Bureau of Statistics; 2011.

[52] Wu XD, Xia XH, Chen GQ, Wu XF, Chen B. Embodied energy analysis for coal-based power generation system-highlighting the role of indirect energy cost. Applied Energy.

2016; 184:936-50.

[53] Jiang P, Keith N. Opportunities for low carbon sustainability in large commercial buildings in China. Energy Policy. 2009;37:4949-58.

[54] Odeh NA, Cockerill TT. Life cycle GHG assessment of fossil fuel power plants with carbon capture and storage. Energy Policy. 2008;36:367-80.

[55] Spath PL, Mann MK, Kerr DR. Life cycle assessment of coal-fired power production.

National Renewable Energy Lab., Golden, CO (US); 1999.

[56] Whitaker MB, Heath GA, Burkhardt JJ, Turchi CS. Life cycle assessment of a power tower concentrating solar plant and the impacts of key design alternatives. Environmental Science \& Technology. 2013;47:5896-903.

[57] Uchiyama Y. Energy techonology life cycle analysis that takes $\mathrm{CO}_{2}$ emission reduction into consideration. CRIEPI. 1995.

[58] Kannan R, Leong KC, Osman R, Ho HK, Tso CP. Life cycle assessment study of solar PV systems: An example of a $2.7 \mathrm{kWp}$ distributed solar PV system in Singapore. Solar Energy. 2006;80:555-63. 
[59] Pacca S, Sivaraman D, Keoleian GA. Parameters affecting the life cycle performance of PV technologies and systems. Energy Policy. 2007;35:3316-26.

[60] Nishimura A, Hayashi Y, Tanaka K, Hirota M, Kato S, Ito M, et al. Life cycle assessment and evaluation of energy payback time on high-concentration photovoltaic power generation system. Applied Energy. 2010;87:2797-807.

[61] Tripanagnostopoulos Y, Souliotis M, Battisti R, Corrado A. Energy, cost and LCA results of PV and hybrid PV/T solar systems. Progress in Photovoltaics Research and Applications. $2005 ; 13: 235-50$.

[62] Lenzen M, Munksgaard J. Energy and $\mathrm{CO}_{2}$ life-cycle analyses of wind turbines-review and applications. Renewable Energy. 2002;26:339-62.

[63] Ardente F, Beccali M, Cellura M, Lo Brano V. Energy performances and life cycle assessment of an Italian wind farm. Renewable and Sustainable Energy Reviews. 2008;12:200-

17.

[64] Crawford RH. Life cycle energy and greenhouse emissions analysis of wind turbines and the effect of size on energy yield. Renewable and Sustainable Energy Reviews. 2009;13:2653-60.

[65] NDRC. The $13^{\text {th }}$ five-year plan for renewable energy development. Beijing: National Development and Reform Commission of China; 2016.

[66] NBS. China Energy Statistical Yearbook. Beijing: China Statistics Press; 2016.

[67] Kennedy C, Steinberger J, Gasson B, Hansen Y, Hillman T, Havránek M, et al. Greenhouse gas emissions from global cities. Environmental Science \& Technology. 2009;43:7297-302.

[68] Lin J, Cao B, Cui S, Wang W, Bai X. Evaluating the effectiveness of urban energy conservation and GHG mitigation measures: The case of Xiamen city, China. Energy Policy. 2010;38:5123-32.

[69] Xi F, Geng Y, Chen X, Zhang Y, Wang X, Xue B, et al. Contributing to local policy making on GHG emission reduction through inventorying and attribution: A case study of Shenyang, China. Energy Policy. 2011;39:5999-6010. 